\title{
CONTRIBUIÇÕES DA GESTÃO ESCOLAR PARA A QUALIDADE DA EDUCAÇÃO
}

http://dx.doi.org/10.5902/2176217110825

\author{
Leticia Degrandi Gelatti \\ Universidade Federal de Santa Maria, Brasil. \\ Lorena Inês Peterini Marquezan \\ Universidade Federal de Santa Maria, Brasil.
}

\begin{abstract}
Resumo
Este trabalho é fruto da pesquisa em uma escola municipal de Santa Maria, RS, sobre os resultados desta no Ideb/2011. O objetivo da pesquisa foi investigar que ações são desenvolvidas pela gestão da escola para facilitar o processo de aprendizagem dos alunos e contribuir para esse sucesso. A metodologia adotou a abordagem quanti-qualitativa, utilizando-se de estudo de caso, entrevista semiestruturada com a equipe diretiva da escola, observação, pesquisa no projeto político-pedagógico da escola e dados quantitativos sobre o Ideb. Como resultados da pesquisa percebeu-se que, nessa escola a democracia é vivenciada na práxis pedagógica e social, bem como as ações que facilitam o sucesso escolar são planejadas e vivenciadas com a participação de toda a comunidade escolar, características de uma educação de qualidade.

Palavras-chave: gestão escolar, avaliação, Ideb, qualidade da educação.
\end{abstract}

\section{CONTRIBUTIONS OF SCHOOL MANAGEMENT IN QUALITY EDUCATION}

\section{Abstract}

This work is the result of research in a municipal school in Santa Maria, RS, on the results of the Ideb/2011. The objective of the research was to investigate what actions are undertaken by the school management to facilitate the learning process of students and contribute to this success. The methodology adopted quantitative and qualitative approach, using case study, semi-structured interviews with the directive team of the school, observation, research on political pedagogical project school and quantitative data on the Ideb. The research results it was realized that this democracy the school is experienced in pedagogical praxis and social, as well as actions that facilitate academic success are planned and lived with the participation of the whole school community, characteristics of a quality education.

Keywords: school management, evaluation, Ideb, education quality. 


\section{Introdução}

O presente trabalho é resultado da pesquisa realizada para a monografia do curso de especialização em Gestão Educacional da Universidade Federal de Santa Maria. O tema apresentado refere-se ao olhar da equipe diretiva da Emef Vicente Farencena, de Santa Maria, RS, sobre os resultados no Ideb.

A escolha desta escola aconteceu a partir do resultado do Índice de Desenvolvimento da Educação Básica - Ideb - do ano de 2012. Superando a média nacional, que em 2011 foi de 5, para os anos iniciais do Ensino Fundamental, e de 4,1 para os anos finais, esta escola atingiu a média 7,2 para os anos iniciais, sendo este 0 maior índice obtido considerando todas as escolas com séries iniciais e anos finais do município de Santa Maria, RS. Esta nota surpreende, pois supera muito as expectativas em relação às escolas públicas.

Desta forma buscou-se conhecer quais as ações que são realizadas pela gestão desta escola para auxiliar no sucesso escolar de seus alunos, aumentando, assim, a sua média no Ideb. Se o "sucesso de uma gestão escolar, em última instância, só se concretiza mediante o sucesso de todos os alunos" (Vieira, 2007, p. 49), pode-se também se afirmar o contrário, que o sucesso da gestão implica no sucesso de seus alunos, bem como dos professores.

Por meio de entrevistas com os gestores da escola, buscou-se: a) investigar quais foram as ações desenvolvidas para facilitar o processo de aprendizagem dos alunos, de forma a superar a média nacional do Ideb, desenvolvendo uma educação de qualidade; b) verificar qual é o papel dos gestores da escola, especialmente equipe diretiva, no planejamento e execução das ações/atividades/projetos que facilitam a aprendizagem escolar de seus alunos; c) refletir sobre o projeto político-pedagógico da escola, as ações que são planejadas, desenvolvidas pela escola que contribuíram para esse sucesso, ou seja, uma educação de qualidade; d) contribuir na divulgação do trabalho de comprometimento, colaborativo, participativo e de qualidade da escola em estudo, em encontros, seminários, congressos locais, nacionais e internacionais.

\section{O sistema de avaliação da educação e o Ideb}

O sistema de avaliação da educação no Brasil é relativamente recente e tema de constantes estudos e debates na área da educação. Até meados da década de 1990 não existiam medidas de avaliação da aprendizagem que demonstrassem, de forma significativa,a situação da qualidade do sistema de ensino brasileiro. O Sistema de Avaliação da Educação Básica - Saeb - foi o primeiro sistema implantado para avaliar a qualidade da educação básica e, a partir de 1995, passou a ser aplicado de dois em dois anos a uma amostragem significativa de estudantes da rede pública e privada de ensino.

A LDB, aprovada em 1996, determinou à União a responsabilidade pela avaliação da educação, como pode ser constatado em seu artigo 9으, inciso VI: "VI - assegurar processo nacional de avaliação do rendimento escolar no ensino fundamental, médio e superior, em colaboração com os sistemas de ensino, objetivando a definição de prioridades e a melhoria da qualidade do ensino" (Brasil, 1996).

A partir deste momento as políticas nacionais de avaliação da educação ganharam destaque e se consolidaram, com a criação de novas avaliações, como o Exame Nacional do Ensino Médio, em 1998, e a Prova Brasil, em 2005. 
Com a regulamentação do decreto n. 6.094/2007, que implantou o Plano de metas compromisso todos pela educação, ficou estabelecido que o Ideb seria 0 indicador da qualidade da educação brasileira. Neste documento, o capítulo 2 é dedicado especialmente ao Ideb, conforme pode ser constatado em seu artigo 3:

Art. 3ํ A qualidade da educação básica será aferida, objetivamente, com base no Ideb, calculado e divulgado periodicamente pelo Inep, a partir dos dados sobre rendimento escolar, combinados com o desempenho dos alunos, constantes do censo escolar e do Sistema de Avaliação da Educação Básica - Saeb, composto pela Avaliação Nacional da Educação Básica - Aneb e a Avaliação Nacional do Rendimento Escolar. (Brasil, 2007)

Desta forma, o Ideb passou a ser o indicador do desenvolvimento da educação básica, combinando as informações do fluxo escolar e o desempenho dos alunos nas avaliações, no caso dos municípios, representado pela Prova Brasil, cálculo este que é representado em uma escala de 0 a 10 . Assim, para que a média do Ideb seja crescente, ano a ano, é necessário que as escolas busquem o sucesso escolar de seus alunos, evitando a reprovação e a evasão.

Os resultados do Ideb também permitem que sejam traçadas metas para o sistema educacional. $O$ indicador é divulgado de dois em dois anos, sendo que a Prova Brasil também é aplicada bianualmente. $O$ objetivo é servir de indicador para a verificação do cumprimento de metas fixadas no termo de adesão (Brasil, 2007). Por se utilizar de dois fatores que indicam uma determinada concepção de qualidade na educação, o rendimento e o desempenho, o ldeb se traduz em um indicador estratégico da atual política educacional de avaliação. Sobre isso Castro (2009) contribui, afirmando que a relevância do Ideb pode ser atribuída a estes dois importantes fatores já citados (rendimento e desempenho), no sentido de que

o desenho do indicador evita que os sistemas de ensino direcionem suas ações para um dos seus componentes, ou seja, uma escola que reprova sistematicamente, fazendo que muitos alunos abandonem os estudos antes de completar a educação fundamental, não é desejável mesmo que os poucos alunos sobreviventes tenham bom desempenho nas provas nacionais. Também não é desejável uma escola que aprova em massa, sem dar atenção à qualidade da aprendizagem de seus alunos, pois não adianta alcançar taxas elevadas de conclusão dos ensinos fundamental e médio, se os alunos aprendem pouco na escola. (Castro, 2009, p. 12)

Sendo assim, os sistemas de avaliação, neste caso o ldeb, mostram-se importantes indicadores da situação educacional brasileira, embora se deva considerar que a qualidade da educação seja algo difícil de medir, por se tratar do fato da educação ser um campo subjetivo e heterogêneo, com resultados nem sempre observáveis e mensuráveis. Sobre isso, Lück (2009) traz uma contribuição bastante significativa acerca dos indicadores da qualidade da educação:

Baseado em exames padronizados e análises estatísticas, esse indicador, constitui-se, portanto, em um instrumento capaz de proporcionar informações significativas e consistentes que permitem aferir o estado e a 
situação de sistemas ou redes de ensino e de escolas e descrevê-los de forma objetiva e facilmente entendível, uma vez que abrange elementos observáveis e mensuráveis. Os indicadores de desempenho da escola servem para apontar sucessos, como também expor dificuldades, limitações e indicar situações que necessitam de mais cuidado e atenção, de modo a orientar a tomada de decisão e a determinação de ações de melhoria e a necessária correção de rumos. Também servem para reforçar as ações bem sucedidas, apontando a sua adequação em relação aos resultados desejados. (Lück, 2009, p. 58)

Em face do que foi exposto, as políticas de avaliação são importantes mecanismos que dão subsídios para a formulação, implantação e monitoramento de políticas públicas para a melhoria da qualidade da educação, sendo mais eficazes aquelas políticas que focam a aprendizagem e os índices de freqüência e aprovação dos alunos, como é o caso do Ideb. Para Castro (2009), o objetivo do sistema de avaliação no Brasil ainda tem outra importante função:

A institucionalização da avaliação educacional no Brasil é hoje, sem dúvida, instrumento fundamental do processo de prestação de contas à sociedade e de enriquecimento do debate público sobre os desafios da educação no país. (Castro, 2009, p. 6)

Ainda no que se refere às contribuições das políticas de avaliação na atualidade, é oportuno reiterar que, além de identificar resultados das aprendizagens dos alunos, a avaliação, a partir da década de 1990, passou a ser um importante instrumento para análise de desempenho das instituições e sistemas educacionais. A avaliação ultrapassa a ideia de quantificar os resultados da escola e torna-se uma fornecedora de informações sobre os alunos, os professores e a escola como um todo, servindo como respaldo para elaboração e políticas e reformas educacionais (Fernandes, 2005, p. 145).

A escola pesquisada obteve, em 2011, uma média bastante superior nos indicadores do Ideb (7,2 nos anos iniciais), um avanço considerável se comparado aos resultados dos anos anteriores e até mesmo com resultados em âmbito nacional. Este avanço crescente dos resultados desta escola pode ser observado nos quadros a seguir, elaborados com base nos resultados disponibilizados pelo Inep.

Quadro 1

Média do Ideb nos anos iniciais do ensino fundamental da Emef Vicente Farencena.

\begin{tabular}{|c|c|c|c|c|c|c|c|c|c|c|c|}
\hline \multicolumn{9}{|c|}{ Ideb observado } & \multicolumn{5}{c|}{ Metas projetadas } \\
\hline 2005 & 2007 & 2009 & 2011 & 2007 & 2009 & 2011 & 2013 & 2015 & 2017 & 2019 & 2021 \\
\hline 5,0 & 5,4 & 5,5 & 7,2 & 5,0 & 5,4 & 5,7 & 6,0 & 6,2 & 6,5 & 6,7 & 6,9 \\
\hline
\end{tabular}

Fonte: Inep. 
Quadro 2

Média do Ideb nos anos finais do ensino fundamental da Emef Vicente Farencena

\begin{tabular}{|c|c|c|c|c|c|c|c|c|c|c|c|}
\hline \multicolumn{5}{|c|}{ Ideb observado } & \multicolumn{6}{|c|}{ Metas projetadas } \\
\hline 2005 & 2007 & 2009 & 2011 & 2007 & 2009 & 2011 & 2013 & 2015 & 2017 & 2019 & 2021 \\
\hline 4,5 & 5,0 & 5,4 & 5,4 & 4,5 & 4,7 & 4,9 & 5,3 & 5,7 & 5,9 & 6,1 & 6,4 \\
\hline
\end{tabular}

Fonte: Inep.

Nos quadros 1 e 2 exibidos acima, veem-se as médias do ldeb para esta escola de 2005 até 2011, bem como as metas projetadas de 2007 até 2021. Conforme exposto nos quadros, nota-se que as médias no Ideb da escola pesquisada permanecem acima das médias nacionais das escolas públicas desde o ano da criação desta política. O mesmo pode ser percebido se comparado às escolas municipais. Tomando como exemplo a fins de comparação, no ano de 2011 a média total do Ideb observada no Brasil nos anos iniciais foi 5,0, enquanto na escola Vicente Farencena atingiu a média 7,2. Uma diferença considerável também pode ser percebida nos anos finais, onde a média da escola pesquisada foi de 5,4, enquanto no Brasil a média total observada foi de 4,1 no mesmo ano.

Ainda com base nos quadros do Ideb da escola pesquisada, pode se perceber que a mesma têm atingido médias que ficam acima das metas estipuladas para os mesmos períodos (2007, 2009 e 2011), tanto nos anos iniciais quanto nos anos finais do ensino fundamental.

\section{Gestão escolar e gestão democrática}

É inegável o fato de que a sociedade atual vive em processo de constantes transformações econômicas, políticas, sociais, culturais, de valores e na forma de ver e interagir no mundo. A escola, por sua vez, se encontra no interior deste processo de mudança e tem o desafio de adaptar-se a esta sociedade cada vez mais dinâmica. Os estabelecimentos de ensino são unidades especiais, são organismos vivos que fazem parte de um contexto socioeconômico e cultural, marcado pela pluralidade e diversidade.

Cabe trazer à discussão o entendimento do que é gestão educacional, de acordo com Heloísa Lück,

a gestão educacional corresponde à área de atuação responsável por estabelecer o direcionamento e a mobilização capazes de sustentar e dinamizar o modo de ser e de fazer dos sistemas de ensino e das escolas, para realizar ações conjuntas, associadas e articuladas, visando o objetivo comum da qualidade do ensino e seus resultados. (Lück, 2006, p. 25)

Desta forma, de acordo com a autora, as ações dos gestores educacionais devem ser articuladas entre si e com a participação de todos no processo, do planejamento à execução, caso contrário, não alcançarão o sucesso almejado. Destaca-se, nestas palavras da autora, a dinâmica necessária na ação dos gestores educacionais e das escolas, necessária para acompanhar as mudanças cada vez mais acentuadas na sociedade.

Com isso, a responsabilidade da gestão educacional vai muito além da simples administração de recursos financeiros, de pessoal ou do patrimônio escolar. Da mesma forma a gestão de uma escola não se resume mais ao seu diretor, que até bem pouco 
tempo, atuava como um gerente, a quem competia zelar pelo cumprimento de normas, determinações e regulamentos que eram ditadas por órgãos centrais (Lück, 2006).

Sobre este aspecto, Paro (2000), esclarece que

administrar uma escola pública não se reduz à aplicação de uns tantos métodos e técnicas, importados, muitas vezes, de empresas que nada tem a ver com objetivos educacionais. A administração escolar é portadora de uma especificidade que a diferencia da administração especificamente capitalista, cujo objetivo é o lucro, mesmo em prejuízo da realização humana implícita no ato educativo. Se administrar é utilizar racionalmente os recursos para a realização de fins determinados, administrar a escola exige a permanente impregnação de seus fins pedagógicos na forma de alcançá-los. (p. 7)

Seguindo o pensamento de Paro, cabe salientar que a gestão escolar das escolas públicas compreende inúmeras ações, dentre elas a condução do trabalho dentro da escola, levando em conta a função social da escola, empregando meios claros e compreensíveis para se alcançar determinados fins.

Para Lück (2000), a mudança de paradigma, que passa da simples administração para a gestão da escola é marcada

por uma mudança de consciência a respeito da realidade e da relação das pessoas na mesma - se assim não fosse, seria apenas uma mudança de modelos. Essa mudança de consciência está associada à substituição do enfoque de administração, pelo de gestão. Cabe ressaltar que não se trata de simples mudança terminológica e sim de uma fundamental alteração de atitude e orientação conceitual. Portanto, sua prática é promotora de transformações de relações de poder, de práticas e da organização escolar em si, e não de inovações, como costumava acontecer com a administração científica. (Ibid., p. 15)

A gestão educacional, neste contexto dinâmico em que o mundo se encontra, tem a necessidade de desenvolver novos conhecimentos, habilidades e atitudes, de forma a ultrapassar esta concepção de gestão como mera administração escolar. É necessário um esforço especial por parte da gestão escolar, no sentido de promover a articulação entre seu talento e energia humana, recursos e processos, visando à transformação dos seus alunos em cidadãos participantes da sociedade.

O termo gestão escolar possibilita ultrapassar o enfoque limitado de administração, levando em conta que os problemas educacionais são complexos e necessitam de visão global e abrangente, assim como ações articuladas, dinâmicas e participativas. Esta mudança, que não é apenas uma questão terminológica, representa novas ideias e estabelece, na instituição escolar, uma orientação transformadora, a partir da rede de inter-relações que ocorrem, dialeticamente, no seu contexto interno e externo.

Percebemos que o conceito de gestão escolar ultrapassa o de administração por ser este mais dinâmico, participativo e

por abranger uma série de concepções não abarcadas por este outro [0 conceito de administração], podendo-se citar a democratização do processo de construção social da escola e realização de seu trabalho, mediante a organização de seu projeto político-pedagógico, o 
compartilhamento do poder realizado pela tomada de decisões de forma coletiva, a compreensão da questão dinâmica e conflitiva e contraditória das relações interpessoais da organização, o entendimento dessa organização como uma entidade viva e dinâmica, demandando uma atuação especial da liderança e articulação, a compreensão de que a mudança de processos educacionais envolve mudanças nas relações sociais praticadas na escola e nos sistemas de ensino. (Lück, 2000, p. 16)

Lück (2006) defende que, paralelamente à adoção do termo gestão na legislação e nas organizações escolares, ocorre principalmente a adoção de princípios e valores mais democráticos no ambiente escolar. Consequentemente, há maior abertura à participação da comunidade escolar no cotidiano da escola, assim como possibilita uma visão mais abrangente dos problemas e necessidades educacionais e da própria organização escolar.

Com esta análise, pode-se afirmar que Gestão educacional significa a gestão de sistemas de ensino e a gestão escolar, onde a ideia de gestão passa por todos os segmentos do sistema, tanto em nível de gestão do sistema de ensinos, quanto em nível de gestão de escolas. Na gestão, os processos pressupõem uma ampla e continuada ação que se estende a dimensões técnicas e políticas que só produzem um efeito real quando unidas entre si.

$\mathrm{Na}$ gestão educacional democrática, pode-se destacar a criação de conselhos dotados de autoridade deliberativa e decisória, a participação da comunidade escolar na escolha dos diretores e o repasse direto de recursos financeiros às unidades escolares como sendo medidas que visam contribuir para a construção de uma escola autônoma.

Percebemos, porém, que as relações do sistema educacional são tecidas no dia-adia, assumindo as características produzidas pelos distintos processos de gestão a que são sujeitas, o que demonstra o papel essencial do diretor escolar na busca por empreender um forte espírito de equipe para cumprir os objetivos educacionais, a partir do trabalho coletivo.

A gestão escolar deve ser democrática, com destaque para o relacionamento entre seus profissionais, que buscam valores como igualdade, liberdade, transparência, honestidade, comprometimento e participação, favorecendo um ambiente saudável, motivador e construtivo. Sabe-se que o trabalho do diretor escolar é necessário, mas que este profissional não tem em suas mãos o controle da produção e das decisões a respeito das políticas do sistema de educação do qual faz parte, como por exemplo, das diretrizes, das metas, dos projetos e dos programas.

\section{Metodologia}

Propôs-se a abordagem quanti-qualitativa para este trabalho pelo fato de ter sido trabalhado com questões subjetivas e particulares a respeito da gestão da escola e da compreensão dos gestores a respeito do sucesso de seus alunos e da gestão da escola, além de dados quantitativos relativos aos índices de avaliação do Ideb.

O estudo de caso foi realizado na Emef Vicente Farencena, Santa Maria, RS, buscando compreender como a gestão desta escola se organiza para contribuir para o sucesso de seus alunos. Os dados foram coletados através de entrevista semiestruturada com os gestores da escola, que responderam questões sobre o papel do gestor no sucesso da escola, as ações realizadas pela escola que garantiram um bom índice no Ideb e a 
participação dos pais no cotidiano escolar. Através da entrevista foi possível estabelecer uma relação mais próxima com o tema investigado e com os sujeitos.

A Escola Municipal de Ensino Fundamental Vicente Farencena está localizada à rua João Fontoura e Souza, s/nº, no bairro Camobi, município de Santa Maria, RS. Atualmente, a escola atende a mais de 400 alunos e conta com um corpo docente de 31 professores. Nas proximidades da escola encontram-se a Universidade Federal de Santa Maria, a Base Aérea e vários pontos comerciais, sendo que este bairro está em constante desenvolvimento. De acordo com o projeto político pedagógico da escola, a comunidade do entorno desta consiste, na sua maioria, em funcionários do comércio, bancos, UFSM, militares da BASM, mas também estão presentes famílias de baixa renda e em situação de vulnerabilidade social.

As entrevistas foram realizadas na escola com a equipe diretiva da mesma e, por motivos de preservação da identidade das entrevistadas, referir-se-á a elas com os pseudônimos. A equipe participante da pesquisa inclui a diretora (professora A), vicediretora (professora $B$ ), coordenadoras pedagógicas (professoras $C$ e $D$ ) e orientadoras educacionais (professoras E e F). Todas as gestoras possuem curso de Especialização em Gestão Educacional e quatro das seis entrevistadas trabalham na escola há 19 anos ou mais.

\section{O que mostraram as gestoras da escola?}

Neste item será apresentada uma análise sobre os objetivos específicos desta pesquisa, com base nas entrevistas das seis professoras que atuam na equipe diretiva da escola Vicente Farencena. A utilização do método de entrevista semiestruturada exige um processo bastante complexo e trabalhoso no momento da sua análise. Mesmo assim, a análise das informações foi elaborada de forma a respeitar integralmente as opiniões de cada uma das gestoras participantes da pesquisa. Para esta análise considerou-se 0 referencial teórico sobre a gestão escolar democrática, formação continuada de professores e participação dos pais no cotidiano escolar.

Questao 1: a escola tem se destacado por uma educação de qualidade, apresentando índices de avaliação no Ideb acima da média nacional. Em relação a isso, ressignifique quais são as ações ou projetos significativos realizados pela escola que contribuem para que isso ocorra?

Professora A: Acho que é os professores trabalharem integrados, de forma interdisciplinar. A participação deles em todos os projetos, reuniões, simpósios, oferecidos pela secretaria de educação, que a escola sempre dispensa pra isso, e projetos que a gente teve em parceria com a universidade. A gente sempre trabalhou em conjunto com a universidade, não só com a federal, mas também projetos com a Unifra, com a Ulbra, também, sempre recebemos contribuições. [...] o que prevalece bastante é o trabalho em conjunto dos professores. [...] E também, acho que uma das coisas que a escola tem é: nós não temos rodízio de professores. Então os professores que entram aqui permanecem por bastante tempo [...]. Então isso também é bom, porque ele se integra bem com o projeto político da escola, conhece bem a escola e o trabalho desenvolvido. 
Conforme é possível perceber nesta fala da diretora, os professores costumam participar dos projetos da escola e suas parcerias, bem como de formações organizadas pela Secretaria de Município da Educação. De posse dessas informações, surgiu uma nova indagação no momento da entrevista: a escola apoia a formação continuada dos professores?.

Professora A: Muito. Sempre, sempre. [...] nós sempre dispensamos, nós da direção vamos para a sala de aula para dispensar o professor. [...] A gente sempre deu incentivo, e a formação continuada mesmo na escola, as nossas reuniões pedagógicas, sempre é focando na formação continuada.

Professora B: Eu acredito que a primeira coisa é o trabalho em conjunto de todo o grupo. Tanto equipe diretiva, como os professores, funcionários e também a comunidade, os pais são bem atuantes. A questão das parcerias com as universidades, também, [...] e que contribuem na formação dos professores. Então isso se reflete nas atividades que são desenvolvidas cotidianamente e também no desempenho dos alunos como um todo. Os professores todos buscam uma formação continuada lá fora, e todos tem especialização, ou cursos de formação continuada mesmo, embora não seja um curso mais formal, [...] no caso da especialização, mas todos, continuamente, buscam essa formação. [...] A escola busca continuamente ver e rever o que está dando certo e o que precisa ser melhorado. Então isso é uma forma da gente conseguir melhorar o desempenho, uma avaliação constante.

Professora C: Acho que a formação dos professores é o ponto de partida, é tudo. Há pouco rodízio de professores, eles dificilmente faltam, deixam de vir. A relação entre eles e a direção é muito boa, de responsabilidade e reconhecimento, aliado ao comprometimento deles com os alunos. Eles se importam muito com a aprendizagem dos alunos [...] A coordenação/ equipe diretiva é uma unidade administrativa, tem uma unidade, ninguém trabalha independente do outro. Os professores confiam na equipe diretiva, apoiam. [...] Os professores são abertos a mudanças e dispostos a sempre melhorar a sua atuação, estão preocupados com a aprendizagem. Procuram se atualizar e trazer coisas novas para os alunos. Há também, a questão da família, os pais reconhecem a escola como forte, eles têm expectativas quanto à escola e os professores têm que corresponder a estas expectativas [...]. A gente vê professor que não falta à escola, se falta tem sempre um ou dois professores prontos pra cobrir. Tem companheirismo, trabalho em equipe, união. Nos anos iniciais antes não tinha biblioteca organizada nem uma pessoa responsável. Faz dois ou três anos que conseguimos organizar e as crianças fazem retiradas de livros toda semana. Tínhamos ano passado o projeto da Hora do Conto. Acho que a leitura é muito importante para o aprendizado nos anos iniciais. A leitura é a base de tudo.

Professora D: Primeiramente, o interesse e responsabilidade do corpo docente bem como sua formação continuada, desenvolvimento de projetos v. 2 ก. 4 Jul./dez. 2013 p. $43-62$ 
que envolvam a Escola como um todo, além da parceria com instituições (UFSM e outros) buscando a melhoria na qualidade de ensino.

Professora E: Em primeiro lugar eu creio que é a experiência profissional dos professores. Porque os professores aqui na escola todos eles têm um tempo de serviço, [...] que passaram por muitas formações. [...] a grande maioria dos professores tem especialização ou mestrado. [...] Outra coisa, os professores são muito dedicados, há uma dedicação muito especial à escola, à função social da escola. Aqui ninguém reclama, são muito dispostos. Acho que isso faz a diferença. Os professores sempre participam de formação continuada. E sempre há um empenho muito grande para que o aluno supere as suas dificuldades, nas mais variadas disciplinas.

Professora F: É resultado do trabalho em conjunto do professor, da equipe diretiva, das parcerias, também, que a gente busca com órgãos, entidades que se disponibilizam à instituição, a Universidade, tudo o que for ajudar o aluno a gente está aberto, a escola está aberta para tudo o que vem para contribuir, para ajudar. [...] a gente aqui na orientação, todas aquelas solicitações que vem por parte dos professores, das dificuldades que eles vêm encontrando em sala de aula, eles passam pra gente e buscamos palestras, profissionais que possas estar ajudando, ou as famílias, ou os alunos, ou mesmo o grupo de professores, buscando dar esse suporte para eles em sala de aula.

De posse desses fragmentos percebemos que todos os sujeitos pesquisados afirmam como sendo de fundamental importância a participação coletiva, a formação continuada dos professores, a presença dos projetos e parcerias com universidades como a UFSM, Ulbra e Unifra e atribuem a estes fatores o sucesso da escola no Ideb.

A participação, o trabalho em conjunto, a relação de respeito e comprometimento e o envolvimento são valores e características recorrentes nas falas das professoras. A participação é um dos princípios básicos da gestão educacional democrática, devendo ser estendida a todos os segmentos da comunidade escolar: professores, alunos, funcionários, pais e comunidade. Para Lück (2001), o próprio conceito de gestão já carrega em si a ideia de participação, onde pessoas trabalham de forma associada analisando situações, trocando experiências e tomando decisões de forma conjunta. Esta mesma autora evidencia que

o desempenho de uma equipe depende da capacidade de seus membros de trabalharem em conjunto e solidariamente, mobilizando reciprocamente a intercomplementaridade de seus conhecimentos, habilidades e atitudes, com vistas à realização de responsabilidades comuns. [...] Por outro lado, a mobilização e o desenvolvimento dessa capacidade depende da capacidade de liderança de seus gestores. (Lück, 2008, p. 97)

Neste sentido, a participação consiste na atuação consciente dos sujeitos no cotidiano escolar, que assumem serem membros de uma instituição social e que têm poder de exercer influência nas tomadas de decisões da escola. Para que isso ocorra é necessário, porém, que as pessoas desejem participar das discussões que envolvem o 
ambiente escolar e que a própria gestão disponibilizem momentos de participação. Reportamos-nos novamente à Lück (2011) quando ela atribui aos responsáveis pela gestão escolar a função de promover a criação de um ambiente que seja favorável à participação no processo educacional, tanto dos profissionais que atuam na escola quanto dos alunos e pais. É através dessa participação, segundo a autora, que os sujeitos desenvolvem a consciência social crítica e o sentido de cidadania, condições necessárias para que a gestão escolar democrática e as práticas escolares promovam a formação dos seus alunos Lück (2011).

A formação continuada é outra característica bem marcante nas falas dos sujeitos pesquisados. Pode-se perceber que todas as professoras que responderam à entrevista consideram a formação continuada dos professores como sendo um dos principais motivos pelo sucesso alcançado pela escola. Os professores desta escola participam das formações promovidas pela escola, durante as reuniões pedagógicas, de eventos de formação promovidos pela Smed e até mesmo buscam por cursos e eventos por conta própria, demonstrando o interesse pela atualização, complementação, avaliação e reflexão crítica da própria prática educativa. No próprio projeto político-pedagógico da escola, consta, como um dos objetivos da formação continuada na escola "refletir sobre as práticas e discutir o papel e a importância da reflexão para o desenvolvimento profissional e pessoal" (Projeto político-pedagógico da Escola Vicente Farencena, p. 51).

Sobre a formação continuada, Nóvoa (1997) argumenta que a formação não se constrói por acumulação (de cursos, de conhecimentos ou de técnicas), mas sim através de um trabalho de reflexidade crítica sobre as práticas e de (re) construção permanente de uma identidade pessoal (Nóvoa, 1997, p. 25, apud Borin, 2010, p. 17).

Assim, o professor é o maior responsável pela sua própria formação, cabendo a ele investir na sua capacitação e na busca por aprimorar a sua prática docente e estar em constante reflexão sobre a mesma.

Questão 2: como gestor escolar, qual é o seu papel na conquista da qualidade da educação pela sua escola?

Professora A: Eu acho que é na condução da equipe. [...] As coordenadoras são incansáveis. O acompanhamento delas com o trabalho com os professores. A formação nossa, também, a formação continuada na gestão, a gente sempre tem feito tudo que foi curso de gestão oferecidos pela secretaria de educação. [...] Outra coisa é o nosso trabalho com a comunidade, também. Trabalho de chamar os pais para a escola, em fazê-los acompanhar os alunos, e um dos nossos maiores problemas da escola é esse, o acompanhamento dos pais nas tarefas de casa. Mas a gente, sempre que tem reunião, sempre que se encontra com os pais, pede que venham à escola, que nos procurem e que procurem os professores, e que a gente tem horários que os professores podem atender. E que a escola é uma escola "aberta" à comunidade [ênfase da professora], a gente quer a participação dos pais. É bem democrática a nossa escola. [...] a gente recebe os pais a todo o momento. Os pais se sentem mais seguros em saber que podem contar com a escola.

Professora B: Eu acho que o papel é justamente acompanhar tanto naquele momento do trabalho com os professores, procurar dar um 
suporte e ver continuamente o que a gente precisava melhorar e rever, buscando melhorar os índices de reprovação [...], de melhoria da aprendizagem propriamente dita, porque nossos índices de reprovação eram baixos, mas mesmo assim, dentro daquele quadro, o que a gente tinha que fazer para melhorar a aprendizagem, para eles terem uma aprendizagem mais significativa. $\mathrm{E}$ hoje, como vice-diretora, buscar sempre manter esse trabalho conjunto, acho que esse é um ponto forte da escola. Manter as parcerias com as universidades e projetos, e com os pais também. Porque não adianta se nós fizermos todo um trabalho aqui, se não tiver esse apoio por parte dos pais não vai refletir. [...]E se eles não nos virem, também, como uma referência, eles não vão fazer a parte deles.

Professora C: Me acho (sic) pouco responsável. Minha parte é mais na questão das reuniões pedagógicas. Acho que o pouco tempo que temos é aproveitado ao máximo. Nas reuniões revemos questões, encaminho o que não está bem. Fizemos ano passado (2012) uma nova pesquisa revendo dificuldades, forças da escola, metas retiradas de uma problemática, que são o que move a escola. O objetivo é fazer mais e melhor a partir de onde já estamos; [...]. Procuro dar apoio aos professores. Outra coisa é a seriedade de liberar os professores para a formação continuada. Quando a SMEd organiza formação continuada [...] nós fazemos de tudo pra liberar. No plano de ação foi apresentado ao conselho escolar e os pais deram como sugestões a leitura, e este ano organizamos o círculo do livro.

Professora D: Promover e incentivar a formação do corpo docente, buscar estratégias para um novo fazer pedagógico que favoreça a construção de conhecimento pelos alunos, trabalhar em parceria com as instituições educacionais proporcionando a inclusão de todos os alunos no ambiente escolar, entre outras.

Professora E: Creio que o papel é o de justamente fazer com que o processo da aprendizagem seja aprimorado a cada ano. E a cada ano a gente vai tendo mais experiências com situações, problemas que vão acontecendo e que a gente vai sempre procurando pesquisar e sanar as dificuldades para que quando venha a ocorrer novamente a gente já tenha uma resposta mais eficaz, já saiba o que fazer. Então, é esse o meu papel dentro da orientação educacional. E muito empenho, eu creio que os orientadores aqui, eles são muito empenhados, tanto a outra orientadora quanto eu, nós não somos aquela orientação parada, nós estamos sempre atrás dos problemas, a gente vai atrás dos problemas, também, não só os problemas vêm atrás de nós. $\mathrm{E}$ a gente tenta resolver.

Professora F: É fazer essa ponte entre o professor, a família e o aluno. Tanto que a nossa estratégia na orientação é: o professor detecta uma situação lá na sala de aula que ele não está conseguindo solucionar ou que ele observou, e ele passa para a orientação e a gente procura conversar com o aluno. Se não surtir efeito a gente chama a família e se não conseguimos resolver assim, encaminhamos o aluno para um 
profissional especializado para que seja avaliado.

A gestão escolar consiste no processo de mobilização e orientação do talento e esforço coletivos presentes na escola, associados com a organização de recursos e processos, instigando, mobilizando competências, superando o enfoque administrativo a partir do reconhecimento da dinâmica humana, promovendo a formação dos professores, dos alunos, inovando, criando espaços de aprendizagens significativas, desempenhando de forma efetiva seu papel social (Lück, 2012).

Conforme a mesma autora, os conceitos de liderança e gestão se complementam, pois não se pode exercer gestão sem liderança. Desta forma, Lück (2012), coloca algumas características dos gestores escolares que agem como líderes, como: liderança compartilhada entre os membros da organização e determinada coletivamente, tomada de decisões distribuída, mediante processos de reflexão e disseminação de informações, sucesso atribuído ao trabalho em conjunto, papeis e funções assumidos de forma compartilhada, segundo o sentido de responsabilidade comum. Por isso, os gestores da escola devem agir de certa forma, como líderes no processo de gestão, de modo a mobilizar e orientar os profissionais dentro da escola.

Através dos fragmentos das falas percebemos que a equipe gestora coloca em prática todas essas características de gestão democrática, participação e liderança citadas pela autora no cotidiano escolar, justificando o sucesso do ldeb.

Ainda nos reportando a Lück, quando salienta a importância da equipe diretiva desempenhar suas funções mobilizando toda a comunidade escolar de maneira participativa, assim se refere:

Realizam gestão; focalizam as pessoas; desenvolvem; apoiam-se em ações de confiança; adotam perspectivas de médio e longo prazos; criam e inovam; são originais; puxam e orientam; são todo-ouvidos; perguntam o que e por quê; aceitam a diversidade aproveitando sua energia para promover a inovação. (Lück, 2012, p. 100)

Comprovamos, pelos quadros apresentados sobre o Ideb, o resultado de um trabalho dinâmico, de intervenção na realidade, de participação coletiva, de educação de qualidade e de liderança aliada ao compromisso com a função social da escola.

Questão 3: analisando o projeto político pedagógico da escola, percebe-se que o mesmo foi construído participativamente com todos os gestores da escola. Os pais têm sido uma presença constante na escola? Comente como conseguiram sensibilizá-los e quais são os momentos abertos para que os mesmos participem do cotidiano da escola?

Professora A: Os pais, para participarem nas atividades da escola, tu tem que proporcionar atividades recreativas, atividades nossas de trabalho, a nossa festa juliana, que é de praxe, campeonatos abertos para os pais, apresentação do Dia das Mães, do Dia dos Pais, encerramento do final do ano com apresentação de Natal. Então é esse chamamento. Nós iniciamos no ano passado um dia de Feira do Livro na escola. Então chamamos escritores locais e eles trazem livros, dão autógrafos, dão palestras, contam histórias para os pequenos e os pais também vêm. Na construção 
do projeto político-pedagógico a gente fez por segmentos. A parte dos pais foi mais por questionários enviados. Enviamos aleatoriamente vários questionários e em cima disso a gente fez um apanhado. Aí, claro, com os alunos, professores e funcionários isso foi feito na escola através de reunião. Com este questionário a gente queria saber a realidade deles. [...] Os dados que estão no projeto político-pedagógico sobre a comunidade foram coletados através deste questionário.

Professora B: Acho, principalmente, que sensibilizar para que eles participem é no momento que eles nos procuram, seja por qualquer motivo, a gente receber bem. Porque aí eles vão se sentir muito mais seguros para participar, para se envolver, vão se comprometer mais, porque eles se sentem parte do processo. Sentir a escola como um ambiente em que ele se sente bem, que ele pode chegar e vai ser ouvido [...]. E os momentos que eles são ouvidos são as assembleias, reuniões, quando tem questionários para que eles participem, a gente faz um primeiro levantamento, depois se faz a discussão em assembleia. E sempre que eles sentem necessidades podem nos procurar. $E$ eles mesmos procuram, é uma característica dos nossos pais. Eles nos apoiam muito, mas eles nos cobram muito também. Então isso acaba refletindo nessa questão do comprometimento, de ambas as partes. A gente tem como uma característica bem diferenciada em relação às outras escolas essa cobrança dos pais, eles são muito presentes. Acho que esse é um diferencial da escola. Eles se envolvem realmente.

Professora C: Eles podem participar no CPM e no conselho, e durante o ano são convidados às reuniões, principalmente no início do ano e no final de cada trimestre. Temos a ideia de que sem a participação dos pais não se faz nada sozinhos, sem eles como parceiros a gente não consegue fazer nada. Eles mesmos propõem reuniões quando estão preocupados e a escola atende. A escola também chama quando sente necessidade. Há as reuniões do Conselho Escolar e do CPM que são sistemáticas. Os pais tiveram participação no Plano de Ação da escola [...]. A participação dos pais é muito importante, pois no momento em que tu coloca para os pais o que está sendo proposto, acaba se comprometendo em cumprir o que tu propôs, eles cobram bastante da escola. Nós nos preocupamos com os nossos alunos e os pais se preocupam com os filhos deles, que são os mesmos, e isso faz com que tenhamos este comprometimento.

Professora D: A escola oferece uma gestão compartilhada nas decisões e informações necessárias a um ensino de qualidade. Os membros da comunidade escolar são envolvidos através de festas, passeios, viagens de estudo, assembleias, palestras, conselho escolar, CPM, e, sempre que solicitados atuam tanto na parte pedagógica como financeira.

Professora E: Os pais são muito participativos aqui. [...] eles acham, assim, que eles têm a obrigação de virem. Então, eles estão sempre muito aqui. Mas uma coisa que eu vejo assim e que contribui bastante é o fato de o SOE fazer muitos chamamentos aos pais, quando o aluno apresenta 
alguma dificuldade de aprendizagem. Então, a presença dos pais aqui é frequente, porque nós chamamos. $E$ os pais sempre querem saber o que está acontecendo com os filhos, então eles vêm. E os pais observam essa dedicação e eles gostam desse interesse. Nós trabalhamos em equipe, nós não ficamos somente aqui no SOE. Quando temos situaçõesproblemas graves, nós vamos todos ali pra sala da direção e em equipe nós resolvemos as coisas, todos participam. E, assim, também, os pais gostam de festas, então é uma coisa que atrai os pais. Nós temos uma grande festa junina, e é essa festa que mobiliza toda a escola, toda a comunidade, e os pais vêm mesmo. $E$ os pais têm um perfil participativo, também. Então, como tem pais com perfil de participação, os outros que não têm começam a observar "puxa, mas esses pais se dedicam tanto!", então um acaba influenciando o outro. Então eles entram aqui na escola e são bem recebidos, são bem atendidos.

Professora F: Participam, com certeza. Essa escola aqui, [...] é uma comunidade muito especial, é uma comunidade que qualquer evento que a escola tenha eles próprios vêm se disponibilizar a ajudar. Todo aluno que chega à escola a nossa primeira ação é fazer uma entrevista com os pais. E nos chama a atenção que já na entrevista eles já dizem "olha, podem me chamar sempre" ou "eu trabalho em 'tal coisa', então se vocês precisarem eu estou à disposição", sabe, eles próprios se dispõe a ajudar. É um diferencial muito grande, que em outras comunidades a gente não percebe, não encontra isso. Isso que vocês estão tentando identificar, qual é a causa desse índice do IDEB, eles também percebem, e talvez por isso já saibam, já vêm com essa expectativa de que "a escola é boa e eu vou ajudar para que seja cada vez melhor, porque o meu filho está estudando nessa escola". Porque é uma disputa muito grande por vagas, assim, no final do ano, no início do ano a gente não dá conta da quantia de gente que quer vir pra cá.

Percebemos que os pais participam da vida escolar de seus filhos. Esse exemplo demonstra que os pais, quando estimulados, aceitos e compreendidos, desenvolvem 0 sentimento de pertencimento, um maior comprometimento e contribuem para a melhoria da qualidade da educação. Na escola, os pais participam da Associação de Pais e Mestres e do Conselho Escolar, o que demonstra o interesse dos mesmos pela escola em que seus filhos estudam.

Os relatos das professoras pesquisadas demonstram que a escola é aberta à participação dos pais, recebendo e chamando para reuniões, festas, elaboração do projeto político-pedagógico e do plano de ação da escola. Para Lück (2011):

Essa participação dos pais na vida da escola tem sido observada, em pesquisas internacionais, como um dos indicadores mais significativos na determinação da qualidade do ensino, isto é, aprendem mais os alunos cujos pais participam mais da vida da escola. (p. 86)

A participação dos pais no cotidiano escolar de seus filhos é importante para a realização de uma gestão democrática, o que é evidenciado pelos relatos das 
professoras. Sobre isso, Lück (2000) afirma que a

educação, portanto, dada sua complexidade e crescente ampliação, já não é vista como responsabilidade exclusiva da escola. A própria sociedade, embora muitas vezes não tenha bem claro de que tipo de educação seus jovens necessitam, já não está mais indiferente ao que ocorre nos estabelecimentos de ensino. Não apenas exige que a escola seja competente e demonstre ao público essa competência, com bons resultados de aprendizagem pelos seus alunos e bom uso de seus recursos, como também começa a se dispor a contribuir para a realização desse processo, assim como a decidir sobre os mesmos. (p. 12)

Portanto, a escola e a família compartilham a responsabilidade pela educação das crianças e jovens, mas cabe à equipe gestora se esforçar para trazer os pais para o ambiente escolar, promovendo meios para isso. Conforme exporto por Valerien (2005), estes chamamentos aos pais podem ser feitos por meios escritos, orais, reuniões, de convívio (festas, quermesses, exposição de trabalhos), visitas às famílias, mensagens aos pais, entre outros (Valerien, 2005, p. 137). Conforme os relatos das professoras participantes da pesquisa, os pais participam da vida escolar de seus filhos das mais diversas formas: no Conselho Escolar, no Círculo de Pais e Mestres, assembleias, reuniões, palestras, atividades recreativas, passeios, viagens de estudo, festa junina, campeonatos, apresentações em datas festivas, feira do livro da escola, além da participação na construção do projeto político-pedagógico e na elaboração do plano de ação da escola.

Questão 4: quais são as ações, experiências e atividades mais significativas para o desenvolvimento de uma educação de qualidade, como as que vocês construíram?

Professora A: A gente tem tentado atender tudo o que os professores nos pedem, desde jogos, atualização do laboratório de informática, livros de literatura, enfim, beneficiar todas as áreas. Esse ano tem a prova do Ideb de novo, então nos anos finais os professores fazem uma espécie de simulado, no primeiro e no segundo semestre, com mais ou menos o que vai cair, com base nas provas de anos anteriores, para prepará-los para a prova. E no 5 ano também os professores focam, em certo período do ano, bem no que vai ser trabalhado na prova. A gente prima por tudo, não só a parte pedagógica, mas também a parte física, porque eu acho que isso também contribui, uma merenda de qualidade para os alunos, que eles tenham um ambiente limpo, um ambiente seguro, que eles tenham atendimento do SOE, na Educação Especial, e este ano até estamos sem, mas já está chegando uma educadora especial. Então o objetivo é que eles sejam bem atendidos em todos os setores da escola, sejam bem acolhidos quando vêm na direção. Acho que não é só na sala de aula, eles têm que se sentir bem na escola, no todo.

Professora B: Eu acho que o que a gente busca cada vez mais e que ainda não chegou é o envolvimento ainda maior [...] com a questão da família ainda, no sentido da aprendizagem propriamente dita. E acho que manter a nossa característica principal, que é esse comprometimento da equipe 
diretiva, a equipe diretiva dando suporte aos professores para que eles possam realizar um trabalho de qualidade e os professores comprometidos com este trabalho, também, e buscando cada vez mais se qualificar [...] nessa avaliação constante que a gente faz, vão surgindo coisas diferentes, alternativas que a gente tem que pensar para manter e melhorar esse índice. A gente não esperava um índice tão alto, então a nossa preocupação agora é manter. Quando a gente coloca sobre um maior envolvimento, ainda, dos pais, é porque embora eles estejam preocupados, há toda uma questão de tempo também. No contexto que nós vivemos hoje, muitas vezes eles não conseguem dar o acompanhamento específico quanto às atividades, na questão das tarefas, o acompanhamento diário. E uma meta mais específica é amenizar a angústia que os professores sentem em relação à educação inclusiva. Nós temos muitos alunos incluídos e é uma preocupação garantir uma aprendizagem dentro das necessidades destas crianças e respeitando as suas diferenças. [...] Pelo contexto, a gente até acha que está conseguindo atender, mas isso está gerando uma angústia muito grande para os professores. Porque eles estão sentindo uma dificuldade, pois no momento nós estamos sem educadora especial, então está faltando a pessoa que dá a sustentação, o suporte para tudo isso. Eles estão se sentindo meio sozinhos.

Professora C: O que estamos lutando ainda é pela adequação curricular para a inclusão. São muitos alunos com necessidades especiais e é difícil atender. A Educadora especial está em licença [...]. Uma coisa boa que está sendo feita agora no município é uma unidade de plano curricular, uma unidade de ação pedagógica, de proposta pedagógica. Assim o currículo é semelhante em toda a rede. Como nos anos iniciais trabalhamos com a interdisciplinaridade, as disciplinas não são trabalhadas de forma separada e a avaliação também é feita desta forma interdisciplinar.

Professora D: a construção do primeiro projeto político-pedagógico da escola, pois através do curso de pós-graduação em Gestão Educacional, minha monografia: A construção de um projeto político-pedagógico da Escola Municipal Vicente Farencena, posso dizer que foi o pontapé inicial e hoje, nota-se que foi de grande importância para a escola, pois, a partir daí surgiram as novas versões. A parceria com a Natura Cosméticos com o projeto Crer para ver através do qual, em anos anteriores, foi conquistado o Laboratório de Ciências e Matemática, fundamentais na aprendizagem dos alunos, auxiliando os professores nas suas práticas pedagógicas.

Professora E: Eu acho que é a unidade; unidade de trabalho; unidade de ação. Acho que quando tu tem um e bom relacionamento uns com os outros, os professores tem um bom relacionamento uns com os outros, afetivo. [...] os professores entre si se dão bem. Sempre tem aqueles que não, a gente sabe, mas há muita discrição, muita ética, e eu acho que isso proporciona uma qualidade [...]. Mas isso tudo é porque todos trabalham há muitos anos uns com os outros. Não é uma coisa, assim, de dois, três 
anos. É dez, vinte, trinta anos trabalhando juntos. Já se conhecem. E uma coisa, assim, [...] que eu acho que também influi é que nós temos aqui muitas professoras que trabalham aqui na escola que foram ex-diretoras, nós temos várias ex-diretoras aqui. Então parece que juntou tudo numa mesma escola várias pessoas com potencial. Ex-diretoras de outras escolas que estão atuando hoje em sala de aula. Olha, eu fui ex-diretora, e pelo menos mais três professoras daqui foram. Então, assim, nós temos um quadro muito bom de professores, de ex-diretores de escola, e na parte da formação, também, especialização, mestrado, então isso tudo conta.

Professora F: Aqui o que eu vejo que é mais significativo é a valorização do profissional. Porque queira ou não queira, quem tem que realmente fazer a diferença é o professor dentro da sala de aula. Se ele não fizer lá dentro da sala de aula, a coisa não muda, a coisa não anda e não teriam esses resultados. E o que se percebe é que aqui eles se sentem acolhidos, se sentem valorizados, se sentem respeitados e eu acho que é isso que todo profissional quer. Embora os órgãos superiores lá fora não deem esse suporte, a gente aqui dentro procura ter essa união, essa cumplicidade de um ajudar ao outro quando precisa, valorizar o lado humano das pessoas e isso faz com que a coisa realmente ande. Assim eles se sentem acolhidos e fortificados para isso.

Percebemos nos relatos dos sujeitos pesquisados que as ações, atividades, projetos são gestados pela comunidade escolar em parceria com várias instituições universitárias. Vimos, nos relatos das professoras, a reflexão sobre a importância da inclusão dos alunos com necessidades especiais, destacando a falta de uma educadora especial, uma das angustias de toda a equipe da escola demonstradas pelas falas.

A equipe gestora percebe a importância do papel dos pais na estimulação e na construção dos conhecimentos e aprendem junto com as famílias, compartilhando os cuidados e educação das crianças e adolescentes, apoiando-se, engajando-se na práxis pedagógica e social. Apesar disso, a equipe diretiva da escola busca cada vez mais este envolvimento dos pais, entendendo que a participação deles é de fundamental importância até mesmo no acompanhamento das tarefas dos filhos, o que parece ser algo insignificante, mas que tem muito valor nos resultados da aprendizagem dos alunos. Em relação a isso, a professora $B$ justifica sobre o porquê do fato de nem todos os pais participarem ativamente da rotina escolar dos filhos, afirmando que no contexto em que vivemos atualmente, muitas vezes eles não conseguem dar o acompanhamento necessário aos filhos devido à falta de tempo.

A maioria da equipe de gestores da escola destaca a necessidade de olharmos as crianças e adolescentes na sua singularidade, ampliando o foco da visão, mirando na diversidade, respeitando as diferenças, buscando formas de inclusão de todos, na dinâmica do cotidiano escolar, de acordo os dispositivos legais da Lei 9394/96 e Constituição Federal de 1988, quando se demonstram preocupadas com a ausência de um profissional de Educação Especial na escola.

Por fim, é possível perceber nas falas de todos os sujeitos da pesquisa que a escola se preocupa com o bom atendimento tanto dos alunos quanto professores, pais e comunidade em geral em todos os aspectos, prezam pela formação e valorização dos 
professores, o comprometimento com a escola, a participação de todos os segmentos da comunidade escolar, o envolvimento, as parcerias estabelecidas entre a escola e outras instituições.

\section{Considerações finais}

Refletindo sobre o papel dos gestores escolares na gestão da escola, buscou-se compreender a atuação destes profissionais na busca para promoverem práxis pedagógicas significativas e ações compartilhadas para 0 aprimoramento da aprendizagem dos alunos nessa escola que obteve média superior no ldeb.

Com base nas pesquisas bibliográficas realizadas e nos relatos dos sujeitos da pesquisa, relacionando também com os dados do Ideb desta escola, verificou-se qual é o papel dos gestores escolares, especialmente da equipe diretiva, no planejamento e execução das ações, atividades e projetos que facilitam a aprendizagem escolar de seus alunos. Observou-se que todos se sentem engajados, motivados, instigados a estimular as crianças e adolescentes no processo de construção de conhecimentos interdisciplinares. É possível afirmar, com base nos relatos das gestoras entrevistadas, que as pessoas que atuam nesta escola praticam uma gestão democrática e participativa, o que contribui e forma bastante significativa para uma efetiva educação de qualidade.

Refletindo sobre o projeto pedagógico da escola, viu-se que as ações que são planejadas e desenvolvidas pela escola contribuíram para o sucesso alcançado pelos alunos, e conseqüentemente pela gestão escolar, incluindo-se equipe pedagógica, pais e comunidade escolar como um todo. Isto porque estes bons índices de avaliação alcançados pela escola são resultado de um trabalho em equipe. Percebe-se que a escola promove uma educação de qualidade, observada na práxis pedagógica e social, na participação coletiva de todos os segmentos da comunidade escolar nas ações planejadas e desenvolvidas pela escola.

Estas falas que foram analisadas demonstram a forte preocupação dos profissionais desta escola com a aprendizagem dos seus alunos e com o ensino oferecido a eles. Mostram também que com o comprometimento de todos com a educação é possível oferecer um ensino de qualidade e promover o sucesso escolar de seus alunos.

Acredita-se que, para se conquistar a tão almejada qualidade na educação, faz-se necessário que a equipe escolar atue de forma a promover uma gestão escolar democrática, destacando o importante papel da equipe diretiva da escola na condução deste processo. Uma escola que promove uma gestão democrática, participativa e com o comprometimento e envolvimento de todos os responsáveis pelo processo de aprendizagem, terá como consequência deste trabalho e esforço a qualidade da educação e o sucesso da escola.

\section{Referências}

BRASIL. Lei n. 9.394/1996, de 20 de dezembro de 1996. Lei de diretrizes e bases da educação nacional, Brasília, DF, 20 dez. 1996. Disponível em: http://www.planalto.gov.br/ccivil_03/Leis/L9394.htm. Acesso em: 12 ago. 2012.

BRASIL. Decreto n. 6.094, de 24 de abril de 2007. Plano de metas compromisso todos pela educação, Brasília, DF, 24 abr. 2007. Disponível em: 
<http://www.planalto.gov.br/ccivil_03/_ato2007-2010/2007/decreto/d6094.htm>. em: 10 jul. 2013

BRASIL. Inep. Portal Ideb. Disponível em: < http://portal.inep.gov.br/web/portal-ideb/portalideb>. Acesso em: 3 jul. 2013.

CASTRO, Maria Helena Guimarães de. Sistemas de avaliação da educação no Brasil: avanços e novos desafios. Revista São Paulo em Perspectiva, São Paulo, v. 23, n. 1, 2009, p. 5-18.

FERNANDES, Cleoni Maria Barboza et al. Formatos avaliativos: trajetória histórica, contradições e impactos em estudantes universitários. In: CUNHA, Maria Isabel (org.). Formatos avaliativos e concepção de docência. Campinas: Autores Associados, 2005, p. 143-162.

LÜCK, Heloísa. et. al. A escola participativa: o trabalho do gestor escolar. Rio de Janeiro: DP\&A, 2001.

LÜCK, Heloísa. Perspectivas da gestão escolar e implicações quanto à formação de seus gestores. Em Aberto, Brasília, v. 17, n. 72, 2000, p. 11-33.

LÜCK, Heloísa. Gestão educacional: uma questão paradigmática. Petrópolis: Vozes, 2008.

LÜCK, Heloísa. Dimensões de gestão escolar e suas competências. Curitiba: Positivo, 2009.

LÜCK, Heloísa. A gestão participativa na escola. Petrópolis: Vozes, 2011.

LÜCK, Heloísa. Liderança em gestão escolar. Petrópolis: Vozes, 2012.

VALERIEN, Jean. Gestão da escola fundamental: subsídios para análise e sugestões de aperfeiçoamento. São Paulo: Cortez, 2005.

VIEIRA, Sofia Lerche. Gestão, avaliação e sucesso escolar: recortes da trajetória cearense. Estudos Avançados, v. 21, n. 60. Disponível em: <http://www.scielo.br/pdf/ea/ v21n60/a04v2160.pdf>. Acesso em: 3 out. 2012.

Leticia Degrandi Gelatti é pedagoga com especialização em Gestão Educacional. Endereço: Rua Eugênio Mussói, 763 - 97070-330 - Santa Maria - RS - Brasil.

E-mail: leticia-Idg@hotmail.com.

Lorena Inês Peterini Marquezan é professora no Cento de Educação da Universidade Federal de Santa Maria.

Endereço: Avenida Roraima, 1000 - prédio 16 - 97119-900 - Santa Maria - RS Brasil.

E-mail: lorenamarquezan@yahoo.com.

Recebido em 29 de setembro de 2013.

Aceito em 25 de outubro de 2013. 